\title{
ISOLAMENTO E CARACTERIZAÇÃO DE BACTÉRIAS DEGRADADORAS DO HERBICIDA DIURON
}

\author{
Milton Ricardo de Abreu Roque ${ }^{1,3 *}$; Itamar Soares de Melo² \\ ${ }^{1}$ Pós-Graduando do Depto. de Microbiologia e Bioquímica, ICB/UNESP, C.P. 199 - CEP: 13506-900 - Rio Claro, SP. \\ ${ }^{2}$ Embrapa Meio Ambiente, C.P. 69 - CEP: 13820-000 - Jaguariúna, SP. \\ ${ }^{3}$ Bolsista FAPESP. \\ *Autor correspondente <mroque@cnpma.embrapa.br>
}

RESUMO: Solos provenientes de áreas cultivadas com cana-de-açúcar, e histórico de utilização do herbicida diuron, foram utilizados para isolamento e caracterização de linhagens bacterianas com potencial de degradar este herbicida. As linhagens foram isoladas de solos da rizosfera de cana-de-açúcar e de solos das entre linhas. Noventa e oito linhagens foram isoladas, das quais 27 foram selecionadas para avaliação do crescimento em meio mineral sólido suplementado com diuron nas concentrações de 5, 10 e $20 \mu \mathrm{gL}^{-1}$. Neste experimento, 5 linhagens apresentaram um crescimento exponencial entre 0-48 horas (EMBRAPA-CNPMA D12-12, D1214 e D16-12) e entre 0-110 horas (EMBRAPA-CNPMA D11-9 e D12-18), similar ao controle. A linhagem EMBRAPA-CNPMA D12-12 identificada como Acinetobacter baumannii, foi selecionada para estudo de cinética de crescimento em meio mineral, com e sem fonte de nitrogênio, com e sem glicose $(0,5 \%)$ e suplementado com diuron nas concentrações 20, 50 e $100 \mu \mathrm{g} \mathrm{mL}^{-1}$, apresentando variação em função da fonte de $\mathrm{N}$, da presença da glicose e da concentração do diuron.

Palavras-chave: Acinetobacter baumannii, biodegradação, herbicidas, curva de crescimento

\section{ISOLATION AND CHARACTERIZATION OF DIURON-DEGRADING SOIL BACTERIA}

\begin{abstract}
Soil samples collected in sugarcane fields with a history of use of the herbicide diuron were employed to isolate and characterize bacterial strains with potential to degrade diuron. Strains were isolated from rhizosphere soil and from soil between plant rows. A total of 98 strains were isolated, of which 27 were selected for further evaluation of pesticide degradation potential at the concentrations of 5,10 and $20 \mu \mathrm{gL}^{-1}$ in mineral agar media. Acinetobacter baumannii strain D12-12 was chosen to study the kinetics of growth in a mineral medium, with and without $\mathrm{N}$, or with and without glucose $(0.5 \%)$ and supplemented with diuron at either 20,50 or $100 \mu \mathrm{g} \mathrm{mL}^{-1}$. In the first experiment, five strains presented exponential growth between 0-48 hours (D12-12, D12-14 e D16-12) or between 0-110 hours (D11-9 e D12-18). Growth of the strain D12-12 was found to vary dependly on the concentration of nitrogen, glucose and diuron.

Key words: Acinetobacter baumannii, biodegradation, herbicide, diuron, growth curve
\end{abstract}

\section{INTRODUÇÃO}

O diuron [3-(3,4-diclorofenil)-1,1-dimetiluréia], pertencente ao grupo químico das feniluréias, é recomendado para aplicação em diversas culturas no Brasil, sendo intensivamente aplicado na cultura de canade-açúcar (Musumeci et al., 1995). Apresenta alta persistência e adsorção ao solo, podendo contaminar solos agrícolas e o ambiente urbano. Segundo Nitschke \& Schüssler (1998), em municípios da Alemanha, o diuron representa $80 \%$ do total de herbicidas encontrados nos efluentes de estação de tratamento de água.

Cripps \& Roberts (1978) e Chakrabarty (1982) relataram a biodegradação e o comportamento do diuron no ambiente. Alfonso Hernandez et al. (1984) observaram que a quantidade de diuron degradado através de processos não biológicos no solo, varia entre 55 a $70 \%$ do ingrediente ativo durante 3 semanas após a aplicação. A taxa aumenta para 80 a $85 \%$ quando ocorre a participação de microrganismos. Musumeci et al. (1995), encontraram taxas de degradação diferenciadas para o solo e para a planta, correlacionando com aspectos da translocação do produto na planta. A degradação de diuron, sob condições anaeróbicas, após 18 dias foi de 85\% (Stepp et al., 1985).

Outra característica do diuron é a toxicidade à organismos do solo e aquáticos, Nebeker \& Schuytema (1998) estudaram o efeito crônico do diuron em peixes e invertebrados e constataram que a sobrevivência e reprodução de Daphnia pulex foi reduzida significativamente quando a concentração de diuron na água era de 7,7 mg L-1. Nemes-Kósa \& Cserháti (1995); Canna-Michaelidou \& Nicolaou (1996) estudaram os efeitos tóxicos e genotóxicos do diuron em fungos e bactérias. A bactéria Acinetobacter baumannii demonstrou capacidade para crescer e utilizar o herbicida diclofopmethyl como fonte de carbono e energia (SmithGreiner \& Adkins, 1996). Dhakephalkar \& Chopade (1994), estudaram a resistência múltipla a metais de 33 isolados clínicos e ambientais de $A$. baumannii. 
Este trabalho teve como objetivos: 1. Isolar linhagens de bactérias, provenientes de solos cultivados com cana-deaçúcar, e com potencial de degradação do diuron; 2. estudar o crescimento e caracterizar as linhagens isoladas.

\section{MATERIAL E MÉTODOS}

\section{Coleta de amostras de solo}

Amostras de solos foram coletadas de regiões produtoras de cana-de-açúcar no Estado de São Paulo, com histórico de aplicações intensivas do diuron (TABELA 1), envolvendo os municípios de Mogi-Mirim, Iracemápolis, Holambra, Limeira e Conchal.

Para coleta de amostras da rizosfera, o sistema radicular de plantas de cana-de-açúcar foi retirado e acondicionado em sacos plásticos de polietileno, e, para a coleta de solo não rizosférico, amostras foram retiradas das entrelinhas de plantio.

TABELA 1 - Relação de locais onde foram coletadas amostras de solos e tipo da amostra: solo rizosférico ou não rizosférico (entrelinhas).

\begin{tabular}{|c|c|c|}
\hline & Amostras Local & Tipo \\
\hline 1 & Mogi-Mirim & solo rizosférico \\
\hline 2 & $\begin{array}{l}\text { Rodovia Piracicaba-Limeira } \\
\text { (Iracemápolis) }\end{array}$ & entrelinhas \\
\hline 3 & Holambra & entrelinhas \\
\hline 4 & Holambra & solo rizosférico \\
\hline 5 & $\begin{array}{l}\text { Rodovia Piracicaba-Limeira } \\
\text { (Iracemápolis) }\end{array}$ & solo rizosférico \\
\hline 6 & $\begin{array}{l}\text { Iracemápolis (Perímetro } \\
\text { Urbano) }\end{array}$ & solo rizosférico \\
\hline 7 & $\begin{array}{l}\text { Rodovia Piracicaba-Limeira } \\
\text { (Iracemápolis) }\end{array}$ & entrelinhas \\
\hline 8 & $\begin{array}{l}\text { Rodovia Piracicaba-Limeira } \\
\text { (Iracemápolis) }\end{array}$ & entrelinhas \\
\hline 9 & $\begin{array}{l}\text { Iracemápolis (Perímetro } \\
\text { Urbano) }\end{array}$ & entrelinhas \\
\hline 10 & $\begin{array}{l}\text { Rodovia Iracemápolis - } \\
\text { Limeira }\end{array}$ & entrelinhas \\
\hline 11 & $\begin{array}{l}\text { Rodovia Piracicaba-Limeira } \\
\text { (Iracemápolis) }\end{array}$ & solo rizosférico \\
\hline 12 & $\begin{array}{l}\text { Rodovia Iracemápolis - } \\
\text { Limeira }\end{array}$ & solo rizosférico \\
\hline 13 & Conchal & solo rizosférico \\
\hline 14 & $\begin{array}{l}\text { Rodovia Limeira - Mogi } \\
\text { Mirim }\end{array}$ & entrelinhas \\
\hline 15 & $\begin{array}{l}\text { Rodovia Limeira - Mogi } \\
\text { Mirim }\end{array}$ & solo rizosférico \\
\hline 16 & $\begin{array}{l}\text { Rodovia Piracicaba-Limeira } \\
\text { (Iracemápolis) }\end{array}$ & solo rizosférico \\
\hline 17 & $\begin{array}{l}\text { Rodovia Piracicaba-Limeira } \\
\text { (Iracemápolis) }\end{array}$ & entrelinhas \\
\hline 18 & $\begin{array}{l}\text { Rodovia Limeira - Eng. } \\
\text { Coelho }\end{array}$ & solo rizosférico \\
\hline 19 & Mogi Mirim & entrelinhas \\
\hline 20 & Conchal & entrelinhas \\
\hline 21 & $\begin{array}{l}\text { Rodovia Limeira - Eng. } \\
\text { Coelho }\end{array}$ & entrelinhas \\
\hline
\end{tabular}

\section{ISOLAMENTO E CONTAGEM DE LINHAGENS} BACTERIANAS

\section{Solo das entrelinhas}

As amostras de solo foram peneiradas (malha de diâmetro de 0,22 mm) e homogeneizadas. Em seguida, foram retiradas subamostras de $10 \mathrm{~g}$, as quais foram adicionadas a Erlenmeyers contendo $90 \mathrm{~mL}$ de solução salina $(0,85 \%)$. Após 15 minutos sob agitação, foram realizadas diluições em série. Alíquotas de $100 \mu \mathrm{L}$ foram retiradas das diluições $10^{-3}, 10^{-4}$, e $10^{-5}$ e semeadas, em triplicatas, no meio de cultura mínimo (MM) (contendo os seguintes produtos por litro: $\mathrm{K}_{2} \mathrm{HPO}_{4}(0,5 \mathrm{~g})$; $\left(\mathrm{NH}_{4}\right)_{2} \mathrm{SO}_{4}(0,5 \mathrm{~g}) ; \mathrm{MgSO}_{4} \cdot 7 \mathrm{~h} 2 \mathrm{O}(0,5 \mathrm{~g}) ; \mathrm{FeCl}_{2} \cdot 1 \mathrm{H}_{2} \mathrm{O}$ $(10 \mathrm{mg}) ; \mathrm{CaCl}_{2}(10 \mathrm{mg}) ; \mathrm{MnCl}_{2}(0,1 \mathrm{mg}) ; \mathrm{ZnSO}_{4}(0,01 \mathrm{mg})$; solução de vitaminas $(2,0 \mathrm{~mL}))$ suplementado com diuron $\left(200 \mu \mathrm{g} \mathrm{mL}^{-1}\right)+$ TTC (cloreto de trifeniltetrazólio $\left.2,5 \mathrm{mg} \mathrm{L}^{-1}\right)$ e com glicose + TTC $\left(2,5 \mathrm{mg} \mathrm{L}^{-1}\right)$. Após 48 horas de incubação a $28^{\circ} \mathrm{C}$, foi realizada a contagem, em unidades formadoras de colônias por grama de solo (UFC $g^{-1}$ de solo).

\section{Solo rizosférico}

Amostras de solo aderido às raízes foram cuidadosamente separadas destas, peneiradas e deixadas para secar por $30 \mathrm{~min}$. a temperatura ambiente. Subamostras de $10 \mathrm{~g}$ foram transferidas para Erlenmeyer contendo $90 \mathrm{~mL}$ de solução salina. Após permanência por 15 minutos sob agitação, os frascos foram deixados por 2 minutos em ultra-som para desagregação de partículas de solo aderidas às raízes. Os procedimentos posteriores foram realizados conforme descrito para o solo das entrelinhas.

\section{CRESCIMENTO DE LINHAGENS BACTERIANAS COM POTENCIAL DE DEGRADAÇÃO DO DIURON}

\section{Meio de cultura sólido}

Neste experimento a seleção de bactérias resistentes e com potencial para utilizar o diuron como fonte de carbono, foi realizada através de testes de crescimento em meio mineral J.E. sólido $\left(\mathrm{K}_{2} \mathrm{HPO}_{4}=0,5\right.$ g; $\left(\mathrm{NH}_{4}\right)_{2} \mathrm{SO}_{4}=0,5 \mathrm{~g} ; \mathrm{MgSO}_{4} \cdot 7 \mathrm{H}_{2} \mathrm{O}=0,5 \mathrm{~g} ; \mathrm{FeCl}_{2} \cdot 1 \mathrm{H}_{2} \mathrm{O}=10$ $\mathrm{mg} ; \mathrm{CaCl}_{2}=10 \mathrm{mg} ; \mathrm{MnCl}_{2}=0,1 \mathrm{mg} ; \mathrm{ZnSO}_{4}=0,01 \mathrm{mg}$; ágar $=15,0 \mathrm{~g}$, por litro de água destilada, Jones \& Edington, 1968) + Diuron (20 $\left.\mathrm{g} \mathrm{m} \mathrm{m}^{-1}\right)$. A avaliação foi realizada após 96 horas. As linhagens bacterianas que apresentaram melhor crescimento, em meio com diuron como única fonte de carbono, foram selecionadas para estudo de cinética de crescimento. Deste modo, 17 linhagens foram submetidas a avaliação de crescimento em meio mineral M9, contendo por litro: $\mathrm{Na}_{2} \mathrm{HPO}_{4}=6,0 \mathrm{~g} ; \mathrm{KH}_{2} \mathrm{PO}_{4}=3,0 \mathrm{~g} ; \mathrm{NaCl}=0,5 \mathrm{~g} ; \mathrm{MgSO}_{4} \cdot 7 \mathrm{H}_{2} \mathrm{O}$ $0,1 \mathrm{M}=10 \mathrm{~mL} ; \mathrm{CaCl}_{2} 1 \mathrm{M}=10 \mathrm{~mL}$; ágar=15,0 g) + diuron nas concentrações de $5 \mu \mathrm{g} \mathrm{mL}^{-1}, 10 \mu \mathrm{g} \mathrm{mL}^{-1}$ e $20 \mu \mathrm{g} \mathrm{mL}^{-1}$, por um período de 7 dias de incubação, à temperatura de $28^{\circ} \mathrm{C}$. 


\section{Meio de cultura líquido}

As linhagens EMBRAPA-CNPMA D11-9, D12-12, D12-14, D12-18 e D16-12, foram selecionadas para os primeiros testes de crescimento em meio de cultura líquido. Foram cultivadas em meio LB (triptona $=10 \mathrm{~g}$; extrato de levedura $=5 \mathrm{~g} ; \mathrm{NaCl}=5 \mathrm{~g}$ por litro de água destilada), tubos de $10 \mathrm{~mL}$, por 24 horas. Após este período, $100 \mu \mathrm{L}$ foram inoculados em meio mineral J.E. acrescido de $20 \mu \mathrm{g} \mathrm{mL}^{-1}$ de diuron, por 24 horas. Após o pré-cultivo, $1 \mathrm{~mL}$ do inóculo de cada linhagem foi introduzido em $100 \mathrm{~mL}$ de meio mineral J.E. suplementado com diuron $\left(20 \mu \mathrm{g} \mathrm{mL}^{-1}\right)$. As avaliações de crescimento foram realizadas pela absorbância em espectrofotômetro Beckman DU-8B, (560 nm), nos intervalos de 48, $110 \mathrm{e}$ 134 horas, após a inoculação. As linhagens EMBRAPACNPMA D11-9, D12-12 e D16-12, foram inoculadas também em meio LB, utilizado como crescimento controle.

\section{Utilização de fonte de carbono e nitrogênio}

A linhagem EMBRAPA-CNPMA D12-12, foi utilizada para verificar a influência da fonte de carbono e de nitrogênio no crescimento bacteriano, em meio de cultura mineral J.E. suplementado ou não com uma fonte extra de carbono (glicose) e com ou sem fonte de nitrogênio. $O$ experimento foi avaliado nos intervalos de 0 - 6 - 24 - 48 - 120 - 168 - 216 horas. A produção do inóculo e montagem foi desenvolvida de acordo com o descrito no item anterior. Em cada intervalo o crescimento foi avaliado através da leitura da absorbância (560 nm) realizadas em espectrofotômetro Beckman DU-8B.

Os meios de cultura utilizados, são descritos a seguir:

1. Meio mineral J.E.+ diuron nas concentrações 20, 50 e $100 \mu \mathrm{gLL}^{-1}$.

2. Meio mineral J.E. $\left(-\mathrm{NH}_{4} \mathrm{NO}_{3}\right)+$ diuron $(0$ (sem adição do herbicida), 20, 50, $\left.100 \mu \mathrm{g} \mathrm{mL}^{-1}\right)+$ glicose $(0,5 \%)$

3. Meio mineral J.E. + diuron $\left(0,20,50\right.$, e $\left.100 \mu \mathrm{g} \mathrm{mL}^{-1}\right)+$ glicose $(0,5 \%)$

\section{RESULTADOS E DISCUSSÃO}

\section{Isolamento e contagem de linhagens bacterianas}

A contagem de células viáveis, apresentando coloração rosa devido a presença de TTC e expressa em unidades formadoras de colônias, por grama de solo (UFC $\mathrm{g}^{-1}$ de solo) ou de raízes (UFC $\mathrm{g}^{-1}$ de raízes) foi realizada após 72 horas de incubação, em meio mínimo suplementado com diuron + TTC e glicose + TTC (TABELA 2). As amostras que apresentaram um maior número de bactérias são na maioria provenientes de solos rizosféricos (TABELA 2).

A comunidade microbiana da rizosfera pode estar relacionada com a capacidade de degradar compostos xenobióticos. Hsu \& Bartha (1979) sugeriram que raízes de plantas podem acelerar a mineralização de pesticidas, por aumentarem a atividade da comunidade ou por selecionarem organismos com capacidade para transformar a molécula alvo.
TABELA 2 - Contagem do número de colônias (UFC x 105/g de solo ou raízes) de bactérias isoladas de solo da entrelinhas e da rizosfera de cana-de-açúcar em meio suplementado com diuron ou glicose, média de 3 repetições.

\begin{tabular}{lcr}
\hline \multirow{2}{*}{ Amostras } & \multicolumn{2}{c}{$\begin{array}{c}\text { Meio de cultura mineral } \\
\text { suplementado com }\end{array}$} \\
\cline { 2 - 3 } & \multicolumn{1}{c}{ Diuron } & \multicolumn{1}{c}{ Glicose } \\
\hline 1 (rizosfera) & $1,9 \times 10^{7}$ & $2,3 \times 10^{7}$ \\
2 (entrelinhas) & $1,2 \times 10^{6}$ & $6,9 \times 10^{7}$ \\
3 (entrelinhas) & $3,6 \times 10^{5}$ & $1,3 \times 10^{7}$ \\
4 (rizosfera) & $1,3 \times 10^{7}$ & $1,9 \times 10^{7}$ \\
5 (rizosfera) & $4,7 \times 10^{5}$ & $7,1 \times 10^{7}$ \\
6 (rizosfera) & $1,1 \times 10^{6}$ & $1 \times 10^{7}$ \\
7 (entrelinhas) & $8 \times 10^{4}$ & $2,7 \times 10^{7}$ \\
8 (entrelinhas) & $2 \times 10^{4}$ & $1,5 \times 10^{6}$ \\
9 (entrelinhas) & $1,1 \times 10^{5}$ & $1,6 \times 10^{7}$ \\
10 (entrelinhas) & $3,3 \times 10^{5}$ & $2,4 \times 10^{6}$ \\
11 (rizosfera) & $1,9 \times 10^{7}$ & $1,3 \times 10^{7}$ \\
12 (rizosfera) & $7 \times 10^{7}$ & $2,3 \times 10^{8}$ \\
13 (rizosfera) & $4,2 \times 10^{7}$ & $2 \times 10^{8}$ \\
14 (entrelinhas) & $1,2 \times 10^{5}$ & $1,7 \times 10^{8}$ \\
15 (rizosfera) & $3,2 \times 10^{5}$ & $2,3 \times 10^{7}$ \\
16 (rizosfera) & $3,2 \times 10^{7}$ & $5,7 \times 10^{7}$ \\
17 (entrelinhas) & $3 \times 10^{5}$ & $1,3 \times 10^{8}$ \\
18 (rizosfera) & $0,7 \times 10^{2}$ & $1,4 \times 10^{8}$ \\
19 (entrelinhas) & $2,2 \times 10^{2}$ & $1,4 \times 10^{7}$ \\
\hline 21 (entrelinhas) & $3 \times 10^{7}$ & $2,5 \times 10^{7}$ \\
\hline
\end{tabular}

A biodegradação de tricloroetileno (TCE) foi maior em solo da rizosfera, quando comparado com o solo não rizosférico (Walton \& Anderson, 1990). Os autores verificaram que, o solo da rizosfera de plantas presentes em uma área contaminada com TCE, apresentou uma evolução de ${ }^{14} \mathrm{CO}_{2}$ 3 vezes maior que o solo da mesma área sem vegetação.

\section{Crescimento das linhagens em meio de cultura sólido}

A seleção das linhagens bacterianas baseou-se em observações macroscópicas de pleno crescimento em meio de cultura M9 e J.E. suplementado com diuron, e características morfológicas, escolhendo colônias diferentes, evitando-se purificar colônias com crescimento lento e irregular (TABELAS 3 e 4).

$\mathrm{Na}$ avaliação de crescimento, as linhagens bacterianas EMBRAPA-CNPMA D12-12 e D12-14 apresentaram nos dois meios de cultura mineral (J.E. e M9) e nas diversas dosagens de diuron, um ótimo crescimento (TABELAS 3 e 4). As linhagens EMBRAPACNPMA D11-9, D12-18 e D16-12 cresceram bem em meio mineral J.E. (TABELA 3), o que não foi observado quando o meio M9 foi utilizado (TABELA 4). 
TABELA 3 - Avaliação de crescimento de linhagens bacterianas em meio mineral J.E. sólido + diuron (20 1234g mL-1) após 96 horas de incubação.

\begin{tabular}{lccccc}
\hline Linhagem & Crescimento & Linhagem & Crescimento & Linhagem & Crescimento \\
\hline D1-9 & -+ & D12-12 & ++ & D13-12 & - \\
D2-5 & -+ & D12-14 & ++ & D15-7 & -+ \\
D2-7 & - & D12-18 & ++ & D15-10 & + \\
D5-6 & -+ & D13-3 & - & D16-2 & + \\
D11-9 & ++ & D13-6 & + & D16-10 & -- \\
D12-7 & - & D13-11 & - & D16-12 & ++ \\
\hline
\end{tabular}

- nenhum crescimento, -- pouco crescimento, -+ crescimento razoável, + crescimento satisfatório, ++ ótimo crescimento

TABELA 4 - Avaliação de crescimento de linhagens bacterianas em meio mineral M9 + diuron, após 168 horas de incubação.

\begin{tabular}{lccc}
\hline Linhagem & \multicolumn{3}{c}{ DIURON $\left.(\mu \mathrm{g} \mathrm{mL})^{-1}\right)$} \\
\hline D1-8 & 5 & 10 & 20 \\
D1-9 & ++ & ++ & -+ \\
D2-5 & ++ & ++ & -+ \\
D5-5 & -+ & -+ & -+ \\
D5-6 & - & - & - \\
D11-9 & -+ & ++ & ++ \\
D12-12 & -+ & -+ & -+ \\
D12-14 & ++ & ++ & ++ \\
D12-16 & ++ & ++ & ++ \\
D12-17 & -+ & -+ & -+ \\
D12-18 & -+ & -+ & -+ \\
D12-20 & -+ & - & -+ \\
D13-7 & -+ & -+ & - \\
D13-13 & ++ & - & ++ \\
D16-2 & -+ & -+ & -+ \\
D16-3 & -+ & - & - \\
D16-12 & - & - & - \\
\hline
\end{tabular}

- nenhum crescimento, -+ crescimento razoável, + crescimento satisfatório, ++ ótimo crescimento

\section{Crescimento das linhagens em meio de cultura líquido}

Baseado nas avaliações iniciais, em meio mineral contendo diuron, as linhagens EMBRAPA-CNPMA D11-9, D12-12, D12-14, D12-18 e D16-12 foram selecionadas para avaliação do crescimento em meio de cultura líquido.

A biodegradação do diuron e a avaliação do crescimento, para o fungo Rhizoctonia solani, foi obtida por Vroumsia et al. (1996). Os autores observaram que o tempo de estabilização do crescimento foi de 120 horas, semelhante ao encontrado neste trabalho para as linhagens bacterianas EMBRAPA-CNPMA D11-9, D12-12, D12-14, D12-18 e D16-12 (Figura 1). A presença de uma fonte de carbono mais facilmente disponível (Meio LB), não alterou a fase inicial de crescimento (Figura 2 ).

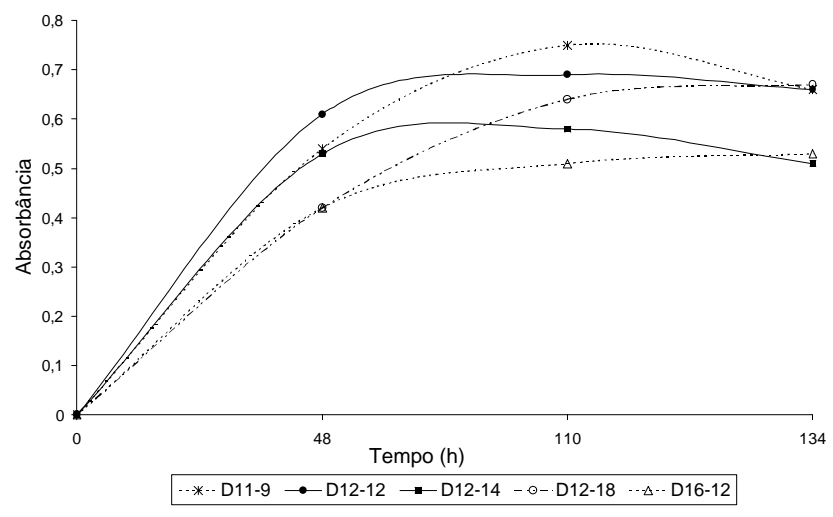

Figura 1 - Crescimento das linhagens EMBRAPA-CNPMA D11-9, D12-12, D12-14, D12-18 e D16-12, em meio mineral mineral J.E. acrescido de $201234 \mathrm{~g} \mathrm{~mL}^{-1}$ de diuron, avaliado nos intervalos de 48, 110 e 134 horas, por espectrofotometria (absorbância a $560 \mathrm{~nm}$ ).

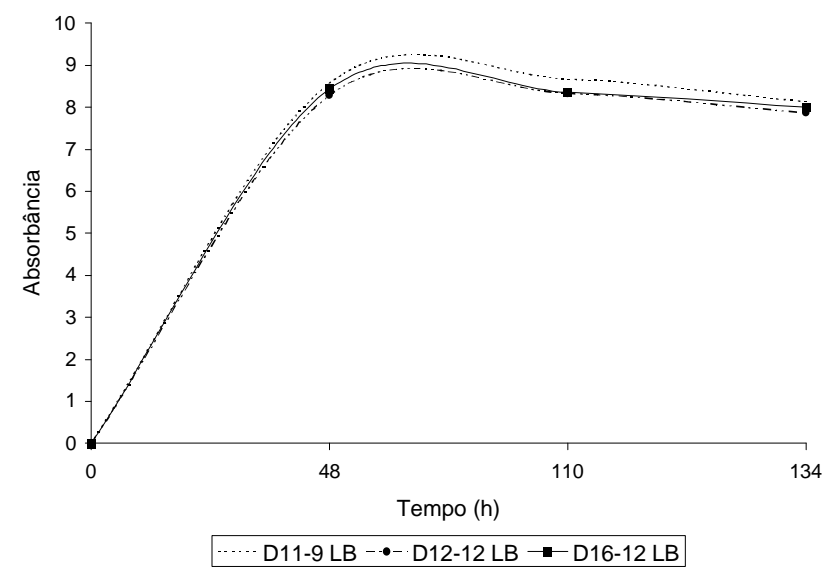

Figura 2 - Crescimento das linhagens EMBRAPA-CNPMA D11-9, D12-12, e D16-12, em meio LB (controle), avaliado nos intervalos de 48, 110 e 134 horas, por espectrofotometria (absorbância a $560 \mathrm{~nm}$ ).

\section{Utilização de fonte de carbono e nitrogênio}

A linhagem EMBRAPA-CNPMA D12-12 apresentou uma fase de adaptação de 6 horas a partir da qual ocorreu crescimento até 24 horas, observou-se uma diminuição no crescimento entre 48-120 horas, independente da concentração de diuron (Figura 3), no meio de cultura 1 (meio mineral suplementado com diuron 
como fonte de carbono). O melhor crescimento da bactéria foi obtido no meio suplementado com diuron e $\mathrm{NH}_{4} \mathrm{NO}_{3}$.

$O$ crescimento da linhagem EMBRAPA-CNPMA D12-12 no meio de cultura suplementado com o diuron nas concentrações de 50 e $100 \mu \mathrm{g} \mathrm{mL}^{-1}$ e glicose aumentou no intervalo de 6 a 24 horas, após este período ocorreu uma diminuição que permaneceu até a última avaliação com 216 horas (Figura 4). Na ausência do diuron (meio 2/0) a linhagem não cresceu, mesmo na presença da glicose. No meio de cultura 3 (diuron + glicose $+\mathrm{NH}_{4} \mathrm{NO}_{3}$, Figura 5), a linhagem manteve a tendência do meio de cultura 2 apresentado na Figura 4, mas somente o meio $3 / 100$ (Figura 5) apresentou crescimento no intervalo entre 6-24 horas.

Shelton et al. (1996), estudaram o metabolismo de 12 herbicidas por Streptomyces, onde a degradação do diuron foi comparada com e sem fonte de nitrogênio $\left(\mathrm{NH}_{4}^{+}\right)$.

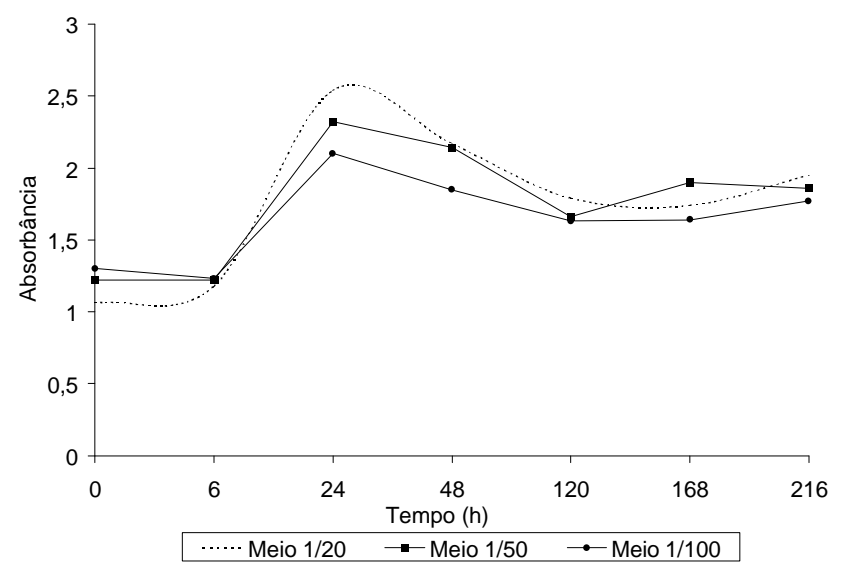

Figura 3 - Crescimento da linhagem D12-12, em meio mineral suplementado com o diuron, nas concentrações de 20, 50 e $1001234 \mathrm{~g} \mathrm{~mL}^{-1}$, avaliado nos intervalos de 0, 6, 24, 48, 120, 169 e 216 horas, por espectrofotometria (absorbância a $560 \mathrm{~nm}$ ).

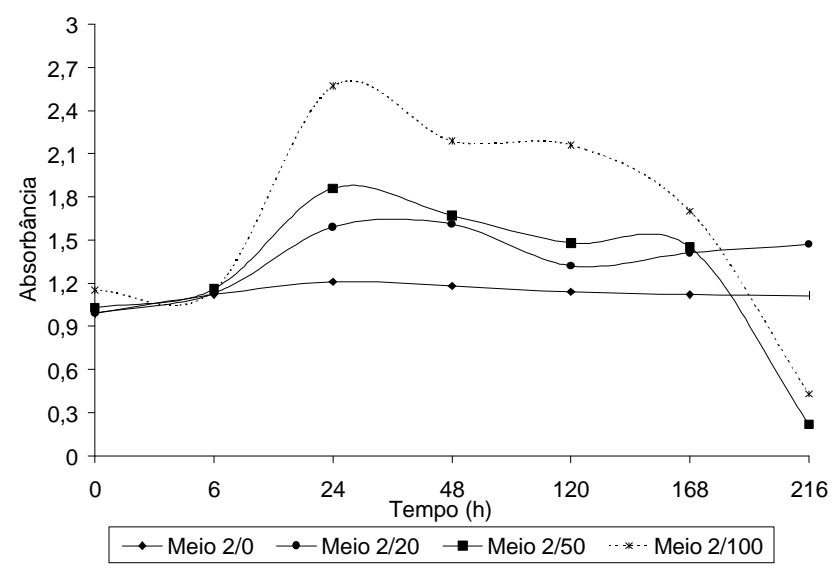

Figura 4 - Crescimento da linhagem D12-12, em meio mineral $\left(-\mathrm{NH}_{4} \mathrm{NO}_{3}\right)$ suplementado com diuron nas concentrações de $0,20,50$ e $1001234 \mathrm{~g} \mathrm{~mL}^{-1}$ e glicose $(0,5 \%)$, avaliado nos intervalos de $0,6,24,48,120,169$ e 216 horas, por espectrofotometria (absorbância a $560 \mathrm{~nm}$ ).
Os autores constataram uma baixa taxa de biodegradação do produto (19\%), sendo esta aumentada na presença de nitrogênio (55\%), após 7 dias de incubação. Estes dados corroboram com os apresentados neste experimento, onde o diuron como fonte de carbono foi importante para o metabolismo bacteriano.

Para compreender a forma de metabolismo e os mecanismos envolvidos na utilização de compostos xenobióticos por microrganismos, se faz necessário um estudo aprofundado do crescimento das linhagens bacterianas, e a utilização do composto alvo como fonte de $\mathrm{N}$ ou carbono. Neste trabalho, pôde-se estudar a cinética de crescimento de Acinetobacter baumannii EMBRAPA-CNPMA D12-12, degradadora do diuron (Roque et al., 1998) e verificar a importância da fonte de nitrogênio e de carbono para a biodegradação. Os melhores resultados foram observados na presença de $\mathrm{NH}_{4} \mathrm{NO}_{3}$; a glicose como fonte de carbono não estimulou o crescimento, sugerindo uma atividade de repressão catabólica na presença de glicose. E, principalmente, a presença do diuron, com ou sem outra fonte de $\mathrm{N}$ ou $\mathrm{C}$, foi o fator seletivo para a ocorrência do crescimento da linhagem EMBRAPA-CNPMA D12-12. Esta característica pode estar relacionada com o local de isolamento da bactéria (solo rizosférico) e com a aplicação do diuron, segundo Sandmann \& Loos (1984), a rizosfera de cana-de-açúcar é rica em exsudatos análogos de moléculas xenobióticas e, a utilização intensiva destas pode promover uma seleção dos microrganismos com mecanismos enzimáticos capazes de biodegradar 0 composto.

\section{Identificação das Bactérias}

Procedeu-se a identificação ao nível de espécie, com a classificação taxonômica sendo realizada na Fundação de Pesquisas Tropicais André Tosello. As linhagens EMBRAPA-CNPMA D12-12, D12-18 e D16-12 foram identificadas como Acinetobacter baumannii.

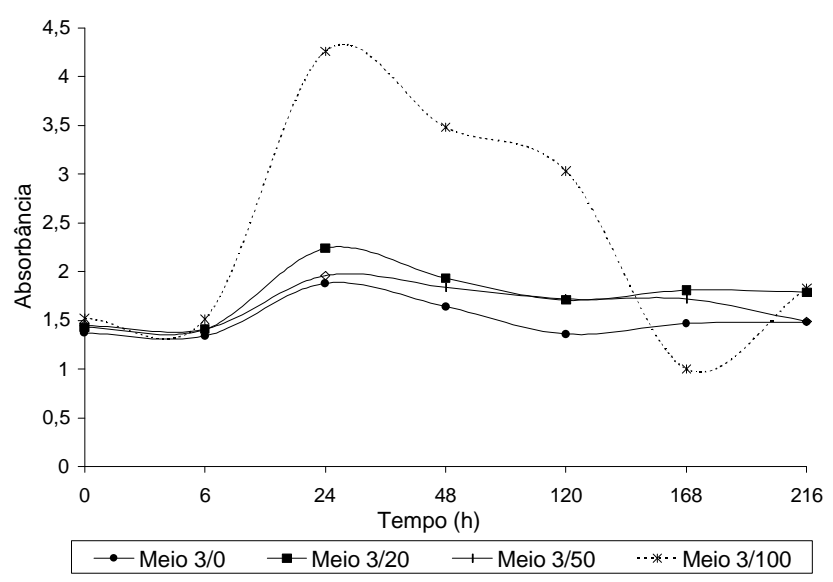

Figura 5 - Crescimento da linhagem D12-12 em meio mineral suplementado com diuron, nas concentrações de 0,20 , 50 e $1001234 \mathrm{~g} \mathrm{~mL}^{-1}+$ glicose $(0,5 \%)$, intervalos de 0 , $6,24,48,120,169$ e 216 horas. 


\section{REFERÊNCIAS BIBLIOGRÁFICAS}

ALFONSO HERNANDEZ, M.M.; MARTINEZ VIEIRA, R.; URDANIVIA, M.L. Descomposición del herbicida diurón por acción de los microorganismos de un suelo ferralítico amarillento lixiviado. Ciencias de la Agricultura, v.19, p.99-104, 1984.

CANNA-MICHAELIDOU, S.; NICOLAOU, A. Evaluation of the genotoxicity potential (by Mutatox ${ }^{\mathrm{TM}}$ test) of en pesticides found as water pollutants in Cyprus. The Science of the Total Environment, v.193, p.27-35, 1996.

CHAKRABARTY, A.M. Biodegradation and detoxification of environmental pollutants. Boca Raton: CRC Press, 1982.

CRIPPS, R.E.; ROBERTS, T.R. Microbial degradation of herbicides. In: HILL, I.R.; WRIGHT, S.J.L.(Ed.) Pesticide microbiology: microbiological aspects of pesticide behaviour in the environment. London: Academic Press, 1978. 844p.

DHAKEPHALKAR, P.K.; CHOPADE, B.A. High levels of multiple metals resistance and its correlation to antibiotic resistance in environmental isolates of Acinetobacter. BioMetals, v.7, p.67-74, 1994.

HSU, T.S.; BARTHA, R. Accelerated mineralization of two organophosphate insecticides in the rhizosphere. Applied Environmental Microbiology, v.37, p.36-41, 1979.

JONES, J.G.; EDINGTON, M.A. An ecologic survey of hydrocarbon-oxidizing microorganisms. Journal of Genetic Microbiology, v.52, p.381-390, 1968.

MUSUMECI, M.P.; NAKAGAWA, L.E.; LUCHINI, L.C.; MATALLO, M.B.; ANDREA, M.M. Degradação do diuron- ${ }^{14} \mathrm{C}$ em solo e em plantas de cana-de-açúcar (Saccharum spp.). Pesquisa Agropecuária Brasileira, v.30, p.775-778, 1995.

NEBEKER, A. V.; SCHUYTEMA, G.S. Chronic effects of the herbicide diuron on freshwater Cladocerans, Amphipods, Midges, Minnows, Worms and Snails. Archives of Environmenta Contamination and Toxicology, v.35, p.441-446, 1998.

NEMES-KÓSA, S.; CSERHÁTI, T. Quantitative structure-activity relationship study on the inhibitory effect of some herbicides on the growth of soil micro-organisms. Journal of Applied Bacteriology, v.79, p.483-491, 1995.
NITSCHKE, L.; SCHÜSSLER, W. Surface water pollution by herbicides from effluents of waste water treatment plants. Chemosphere, v.36, p.35-41, 1998.

ROQUE, M.R.A.; FERRACINI, V.L.; MELO, I.S. Avaliação do berbibida diuron utilizando extração em fase sólida. Jaguariúna: EMBRAPA, CNPMA, 1998.15p. (Boletim de Pesquisa, 3).

SANDMANN, E.R.I.C.; LOOS, M.A. Enumeration of 2,4-Ddegrading microorganisms in soils and crop plant rhizospheres using indicator media; high populations associated with sugarcane (Saccharum officinarum). Chemosphere, v.13, p.1073-1084, 1984.

SHELTON, D.R.; KHADER, S.; KARNS, J.S.; POGELL, B.M. Metabolism of twelve herbicides by Streptomyces. Biodegradation, v.7, p.129-136, 1996.

SMITH-GREINER, L.L.; ADKINS, A. Isolation and characterization of soil microorganisms capable of utilizing the herbicide diclofop-methyl as a sole source of carbon and energy. Canadian Journal Microbiology, v.42, p.221-226, 1996.

STEPP, T.D.; CAMPER, N.D.; PAYNTER, M.J.B. Anaerobic Microbial degradation of selected 3,4-dihalogenated aromatic compounds. Pesticide Biochemistry and Physiology, v.23, p.256-260, 1985.

VROUMSIA, T.; STEIMAN, R.; SEIGLE-MURANDI, F.; BENOITGUYOD, J.L.; KHADRANI, A. Biodegradation of three substituted phenylurea herbicides (chlortoluron, diuron, and isoproturon) by soil fungi. a comparative study. Chemosphere, v.33, p.2045-2056, 1996.

WALTON, B.T.; ANDERSON, T.A. Microbial degradation of trichloroethylene in the rhizosphere: Potential application to biological remediation of wastes sites. Applied Environmental Microbiology, v.56, p.1012-1016, 1990.

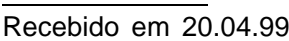

